\title{
The Relationship Between Economic Growth, Energy Consumption and Environmental Pollution Based on ARDL Model
}

\author{
Kim Jong $\mathrm{Chol}^{1,2^{*}}$ \\ ${ }^{1}$ School of Humanities \& Law, Northeastern University, Shenyang 110169 China \\ ${ }^{2}$ School of control Science, University of Science, Pyongyang 526890 DPR of Korea \\ *Corresponding author. Email: jinzhengzhe922@163.com
}

\begin{abstract}
This paper investigated the dynamic relationship among the per capita national income, energy consumption and environmental pollution based on the ARDL model for Liaoning Province. The results of the ARDL model estimation did not clearly confirm the EKC hypothesis that the relationship between economic growth and environmental pollution was inverted U-shaped, but it was estimated that is likely to be the case. The long-run results indicate energy consumption has a positive and significant impact on environmental pollution. The impact of energy consumption on the environmental pollution emissions showed a significant positive relationship at the $5 \%$ level, and $1 \%$ increase in the energy consumption will lead to $0.77 \%$ increase in the environmental pollution emissions. CUSUM and CUSUMSQ tests results show that all coefficients of the model are stable.
\end{abstract}

Keywords: economic growth, Kuznets curve, ARDL model, environmental pollution, Liaoning Province

\section{INTRODUCTION}

Economic development is dependent on energy, and energy consumption inevitably leads to environmental pollution. In recent decades, the word is facing challenges to find a solution to make a balance sustainable economic development and environmental damage. The research on the long-run relationship between economic growth, energy consumption and environmental pollution has important theoretical and practical significance for ensuring the high quality and stable economic growth, reducing energy consumption, optimizing energy structure and reducing environmental pollution. Many theories have been employed to study and assess the relationship between the environment and economic growth.

The environmental Kuznets curve(EKC) theory, first introduced by Grossman \& Krueger(1991), it means that environmental pollution increases during the early stages of economic growth, but that environmental pollution naturally decreases as economic growth progresses and income levels rise[1].

The Environmental Kuznets Curve theory is found to be the best theory to describe the relationship between economic growth and environmental degradation, in which the environment will become better when the economy grows highly[2]. Liaoning Province is one of the important industrial bases in the northeast China, and plays a very important role in the country's economic development. Liaoning's per capita GDP increased from 11177 yuan in 2000 to 54,745 yuan in 2017 , and the energy consumption increased from 987.72 million tons in 2000 to 202.513 million tons in 2017. However, rapid economic growth is usually accompanied by increased energy consumption and many cause unexpected effects on energy resources and the environment. The study examines the dynamic relationships between economic growth, environmental pollution and energy consumption for Liaoning Province based on Environmental Kuznets Curve approach and Autoregressive Distributive Lag (ARDL) bound testing for a long-run relationship. The results of this study do not clearly show the existence of an EKC for Liaoning Province. However, it is estimated that a further economic growth will result in an inverted U-shaped. The long-run results indicate energy consumption has a significant impact on environmental pollution, and the impact of energy consumption on the environmental pollution emissions showed a significant positive relationship at the $5 \%$ level, and $1 \%$ increase in the energy consumption will lead to $0.77 \%$ increase in the environmental pollution emissions.

The paper is organized as follows. Section 2 reviews relevant literature. In section 3 , the ARDL model is constructed considering the economic development of Liaoning Province, and the empirical results are discussed in section 4. Finally, conclusions are summarized in section 5 .

\section{LITERATURE REVIEW}

In general, numerous studies have been conducted on the relationship between economic growth, energy consumption and environmental pollution. The 
environmental Kuznets curve theory is considered as the relationship between economic growth and environment and is one of the most heavily debated issues within environmental economics[3,4,5,6,7]. Environmental Kuznets curve theory reveals the relationship between economic growth and environmental pollution, which represents a reduced form that conceals other phenomena such as technology, product composition, environmental regulations, or demands of society[4,8]. In this sense, this reduced form does not allow initial identification of the effects of economic policy. To illustrate this hypothesis, the authors applied the cross-section panel approach, taking as variables some comparable measures of the partners, among which was air pollution in several urban areas. In the analysis of [4], it was observed that sulfur dioxide and smog in the air increase with the presence of lower GDP per capita. However, this contamination decreases as income increases, indicating statistical evidence of the existence of a relationship between the ECK and the two environmental quality indicators used. The inflection point or the level at which pollution indicators begin to decrease was determined in a range of GDP per capita between 4000 and 5000 dollars. On the contrary, for the specific case of sulfur dioxide and smog, a point of change was not identified; however, the relationship between pollution with these indicators and GDP per capita was perceived as a monotonous increase. In the same way, Alvarado \& Toledo documented the intensity of toxicpro duction for the manufacturing sectors in several countries[9]. This document aimed to determine the environmental effect that manufacturing industries received and to analyze whether their contribution to pollution varied with respect to different incomes. The results obtained indicated the existence of a relationship between the ECK and the intensity of toxic elements per unit of GDP. By employing the Bayer-Hanck combined cointegration and Autoregressive Distributed Lag (ARDL) techniques, You W, Lv Z and Saint Akadiri et al.find a non-significant negative impact of globalization on CO2 emissions in Turkey[10,11,12]. By using a similar approach, Destek and Ozsoy investigate the impact of globalization on the environmental indicators by incorporating urbanization and energy consumption in the framework of the EKC hypothesis[13]. Moreover, the nexus of electricity consumption and the environment in the context of pollutant emissions has been well covered for different cases. For instance, Cowan et al find the Granger causality from electricity consumption to $\mathrm{CO} 2$ emissions in India[11]. Also, Salahuddin et al implement the ARDL approach to study the effect of electricity consumption on carbon emissions, the statistical evidence of Granger causality from electricity consumption to $\mathrm{CO} 2$ emissions is significant and positive[12]. Although the subject of this study is an extensively evaluated area in the educational and research arena, the relationship between economic growth and urbanization has received continuous attention from policy makers and in academic circles. In our study, we accomplish the ARDL-bound testing approach to explore the linkage between energy consumption, economic growth, and environmental pollution for Liaoning Province, and to find out the potential causes of contaminated environment and provide solution for the hidden issues of fumes.

\section{ANALYSIS MODEL}

Autoregressive distribution lag (ARDL) is a least-square estimation model, whose main idea is to determine whether there is a co-integration relationship between variables based on boundary test, and estimate the correlation coefficient between variables. Initially proposed by Charemza \& Deadman[14], and later perfected and popularized by Pesaran et al.[15]. The advantages of the ARDL model are as follows : (1) when testing the long-term relationship between variables, it is unnecessary pre-test on time series; (2) the ARDL estimation results are robust enough even in small samples; (3) when the explanatory variable is endogenous, the ARDL model can also obtain an unbiased and effective estimate; (4) ARDL method overcomes the problems that non-stationary time series brought, such as spurious regression problem[15].

In light of the real situation of the economic and social development of Liaoning Province, the model variable selection is as follows. Sulfur dioxide and TSP(total suspended particulate) emissions from Liaoning Province are taken as an analytical variable, and its value is taken as natural $\log$, and $\operatorname{lnE}$ represents environmental pollution. The basic model of this paper is set as follows:

$$
\begin{aligned}
\ln E_{t} & =\beta_{0}+\beta_{1} \ln X_{t}+\beta_{2}\left(\ln X_{t}\right)^{2}+ \\
& +\beta_{3} \ln E n_{t}+\varepsilon_{t}
\end{aligned}
$$

Where, $E_{t}$ is Sulfur dioxide and TSP emissions, $X_{t}$ represents per capita real GDP, $\mathrm{En}_{\mathrm{t}}$ stands for the energy consumption, $\varepsilon_{\mathrm{t}}$ is the standard error term and $\mathrm{t}$ refers to the time period. $\beta_{1}, \beta_{2}$ and $\beta_{3}$ represent the long-run elasticity estimates of the Sulfur dioxide and TSP emissions with respect to real GDP, the square of real GDP and energy consumption respectively.

Generally, it is expected that the higher level of energy consumption should result in greater economic activity and stimulate the Sulfur dioxide and TSP emissions. Therefore, it is expected that $\beta_{3}$ to be positive. Under the EKC hypothesis, the sign of $\beta_{1}$ is expected to be positive which captures the initial increase in the Sulfur dioxide and TSP emissions as income increases, whereas a negative sign is expected for $\beta_{2}$ which reflects the inverted U-shape pattern once income passes the threshold level [2]. On the basis of the above mode, to examine long-run equilibrium relationship between the Sulfur dioxide and TSP emissions, 
based on AIC, ARDL $(1,3,3,2)$ was valid for $\operatorname{Eq}(1)$. The long-term coefficients of the estimated equation by the optimal ARDL model are shown in Table 2.

Table 2: The estimation results for the ARDL Model (Dependent variable $\ln E_{t}$ )

Where, $\Delta$ represents the first difference and $\alpha_{\mathrm{i}}$ is drift component and $\mu_{\mathrm{i}}$ white noise. The terms $\beta_{\mathrm{i}}, \delta_{\mathrm{i}}, \sigma_{\mathrm{i}}, \epsilon_{\mathrm{i}}$ denote the error correction dynamics while the terms $\alpha_{1}, \alpha_{2}, \alpha_{3}$ and $\alpha_{4}$ correspond to the long run relationship.

In this paper, the boundary test method is used to test the relationship between variables, the value of $F$ statistic is used to test whether there is a long run stable relationship between variables and then the coefficient of the long run relationship between variables in the ARDL model is further estimated.

\section{EMPIRICAL RESULTS AND DISCUSSION}

The indicators of environmental pollution may use various environmental pollution indicators, such as sulfur oxides (SOx, SO2), nitrogen oxides (NOx, NO2), carbon monoxide (CO), carbon dioxide (CO2) and total suspended particulate(TSP). The paper used sulfur dioxide and TSP data to explain the relationship between economic growth, energy consumption, and environmental pollution. The basic statistics of the variables used for the empirical analysis were the data of Liaoning Province Statistics Bureau data of 2000-2018. The unit root tests of the variables are required before estimating the ARDL model.

In this work, the unit root test of variables was performed using the ADF(augmented Dickey-Fuller) and PP(Phillips-Perron) tests. The results of the unit root test are shown in Table 1.

Table 1: Unit root tests

\begin{tabular}{|c|c|c|c|c|}
\hline \multirow[b]{2}{*}{ variable } & \multicolumn{2}{|c|}{$\mathrm{ADF}$} & \multicolumn{2}{|c|}{ PP } \\
\hline & $\mathrm{t}$-Statistic & $\begin{array}{c}1 \text { st } \\
\text { difference }\end{array}$ & t-Statistic & $\begin{array}{c}1 \mathrm{st} \\
\text { difference }\end{array}$ \\
\hline $\ln E_{t}$ & $\begin{array}{c}- \\
2.571125\end{array}$ & $-4.643672^{*}$ & -1.449989 & $-4.878318^{*}$ \\
\hline $\ln X_{t}$ & 1.561488 & $-2.966175^{* *}$ & -1.477424 & $\begin{array}{c}- \\
2.427644 * *\end{array}$ \\
\hline$\left(\ln X_{t}\right)^{2}$ & $\begin{array}{c}- \\
1.473648\end{array}$ & $-2.864504 * *$ & -1.371011 & $\begin{array}{c}- \\
2.509881 * *\end{array}$ \\
\hline $\ln \mathrm{En}_{\mathrm{t}}$ & $\begin{array}{c}- \\
1.893041 \\
\end{array}$ & $-5.787082^{*}$ & -1.917782 & $-5.224284^{*}$ \\
\hline
\end{tabular}

Note: $(*)$ and $(* *)$ indicate $1 \%$ and $5 \%$ level of significance.

The test results show that all variables are not stable at the $5 \%$ or $10 \%$ level of significance, while the differential variables are stable at the $5 \%$ level of significance. Therefore, it was confirmed that all of the time series data recovered stability after the first difference and conforms to the requirements of ARDL model. As a result of estimating ARDL model considering the each variables

\begin{tabular}{cccc}
\hline variable & Coefficient & Std.error & t-Statistic \\
\hline Constant & -32.60633 & 9.92318 & $2.734700^{*}$ \\
$\ln X_{\mathrm{t}}$ & 11.40416 & 3.187963 & $3.459000^{*}$ \\
$\left(\ln \mathrm{X}_{\mathrm{t}}\right)^{2}$ & -0.898732 & 0.284172 & $-3.162633^{*}$ \\
$\ln \mathrm{En}_{\mathrm{t}}$ & 0.774335 & 0.457509 & $2.692501^{*}$ \\
\hline R-squared & & 0.9966178 & \\
\hline
\end{tabular}

Note: $(*)$ indicate $1 \%$ level of significance.

Based on the estimated ARDL model, the energy consumption was found to have a significant positive relationship with environmental pollution emissions at the $5 \%$ level in the long-run. The coefficient of the per capita real GDP is positive(+) and the coefficient of the per capita real squared is negative(-) at the $1 \%$ level. According to Table 3,1\% increase in per capita real GDP will lead to $11.4 \%$ increase in the environmental pollution emissions in long-run.

In addition, the impact of energy consumption on the environmental pollution emissions showed a significant positive relationship at the $5 \%$ level, and $1 \%$ increase in the energy consumption will lead to $0,77 \%$ increase in the environmental pollution emissions.

In other words, the economic growth increases environmental pollution emissions, and at the same time, the increase in environmental pollution emissions implies the reverse relation between economic growth and environmental pollution, which reduces GDP by harming people's health. Economic growth and increased environmental pollution occur almost simultaneously. In other words, economic growth increases energy consumption and increases in energy consumption use increases air pollutants and greenhouse gas emissions.

Table 3: The result of error correction for the selected ARDL model

\begin{tabular}{cccc}
\hline variable & Coefficient & Std.error & t-Statistic \\
\hline$\Delta$ Constant & 21.40614 & 5.187963 & $3.218324^{*}$ \\
$\Delta \ln X_{\mathrm{t}}$ & 1.557953 & 0.169150 & $2.921047^{* *}$ \\
$\Delta\left(\ln \mathrm{X}_{\mathrm{t}}\right)^{2}$ & -0.824328 & 0.058912 & $-3.992623^{*}$ \\
$\Delta \ln \mathrm{En}_{\mathrm{t}}$ & 1.846066 & 0.130618 & $4.133312^{*}$ \\
$\mathrm{ECM}(-1)$ & -0.617213 & 0.146209 & $-4.359389^{*}$ \\
\hline $\mathrm{R}$-squared & 0.995578 \\
\hline Adj R- \\
camarad & 0.993672 \\
\hline Note: $(*)$ and $(* *)$ indicate 1\% and 5\% level of significance. \\
\hline
\end{tabular}

The coefficients cumulative sum (CUSUM) and cumulative sum of squares (CUSUMSQ) were employed 
agreements in reducing sulphur emissions[J],

to check the stability of the analytical model. The CUSUM and CUSUMSQ statistics tests the stability of the estimated coefficients and the stability of the error term. The analysis results show that the model is stable because the critical line moves within the 5\% significance level, and the estimated coefficients of the model are also stable.

\section{CONCLUSION}

This study examined the long-run relationship between the per capita real GDP, energy consumption and environmental pollution based on the ARDL model for Liaoning Province. Although the EKC hypothesis that the relationship between economic growth and environmental pollution is inverted U-shaped was not clearly confirmed, it is estimated that this is likely to be the case. Increasing the per capita real GDP by $1 \%$ can raise the environmental pollution emissions to $11.4 \%$, and $1 \%$ increase in the energy consumption will lead to $0.77 \%$ increase in the environmental pollution emissions. The result of CUSUM and CUSUMSQ tests indicated that all coefficients in the short and long-run models are stable.

\section{REFERENCES}

[1] Dinda S. Environmental Kuznets curve hypothesis: A survey [J],Ecological Economics, 2004, 49(4): 431455 .

[2] Kuznets S • Economic growth and income inequality[J], American Economic Review , $1955,45(1): 1-28$

[3] Grossman G.M., Krueger A.B. Economic Growth and the Environment.Quarterly Journal of Economics $[\mathrm{J}]$, $1995,110(2): 353-377$

[4] Chowdhury R R., Moran E F. Turning the curve: A critical review of Kuznets approaches[J], Applied. Geography. 2012 , 32:3-11.

[5] Correa Restrepo, F. Crecimiento econ ó mico, desigualdad social y medio ambiente: Evidencia emp í rica para América Latina[J], Revista Ingenierías Universidad de Medellín 2007, 6, 12-30.

[6]. Delbianco F, Dabús C, Caraballo M Á. Income inequality and economic growth: New evidence from Latin America[J], Cuadernos de Economía 2014, 33(63), 381-398.

[7] Galeotti,M.; Lanza,A.; Pauli,F. Reassessing the environmental Kuznets curve for CO 2 emissions: A robustness exercise[J], Ecological Economics. 2006, 57(1), 152-163

[8] De Bruyn S M. Explaining the environmental Kuznets curve: Structural change and international
Environment and Development Economics. 1997, 2, 485-503

[9] Alvarado R, Toledo E. Environmental degradation and economic growth: Evidence for a developing country[J], Environment Development \& Sustainability. 2017, 19, 1205-1218.

[10] You W, Lv Z, 2018. Spillover effects of economic globalization on $\mathrm{CO} 2$ emissions: a spatial panel approach[J], Energy Economics. 2018, 73, 248-257.

[11] Cowan W N, Chang T, Inglesi-Lotz R. The nexus of electricity consumption, economic growth and $\mathrm{CO} 2$ emissions in the BRICS countries[J], Energy Policy 2014, 66, 359-368.

[12]. Salahuddin M., Alam K., Ozturk I. The effects of electricity consumption, economic growth, financial development and foreign direct investment on $\mathrm{CO} 2$ emissions in Kuwait[J], Renew. Renewable and Sustainable Energy Reviews. 2018, 81, 2002-2010.

[13] Destek M A, Ozsoy F N. Relationships between economic growth, energy consumption, globalization, urbanization and environmental degradation in Turkey[J], International Journal of Energy and Statistics, 2015, 3(4), 1550017.

[14] Wojciech W. Charemza and Derek F. Deadman. New Directions in Econometric Practice, General to Specific Modelling, Cointegration and Vector Auto Regression[J], Pakistan Development Review, 2015,54(1), 73-85.

[15] Pesaran M H,Shin Y An autoregressive distributed lag modeling approach to cointegration analysis[M], Econometrics and economic theory in the 20th century,1999, 31(7) 371-413.

[16] Mohammadi H, Amin M D. Long-run relation and short-run dynamics in energy consumption-output relationship: International evidence from country panels with different growth rates $[\mathrm{J}]$, Energy Economics, 2015(52): 118-126.

[17] Pesaran M H, Shin Y, Smith R J. Bounds testing approaches to the analysis of level relationships [J], Journal of Applied Econometrics, 2001, 16(3): 289-326.

[18] Lee C C. Energy consumption and GDP in developing countries:A cointegrated panel analysis [J], Energy Economics, 2005,27(3): 415-427

[19] Pesaran M H, Shin Y, Smith R J. Bounds testing approaches to the analysis of level relationships [J], Journal of Applied Econometrics, 2001, 16(3): 289-326. 
[20] Altinay, G. and Karagol, E. Electricity Consumption and Economic Growth:Evidence from Turkey[J], Energy Economics 2005, $27: 849-856$.

[21] Yildirim, E • , Sukruoglu, D · , Aslan , A - Energy Consumption and Economic Growth in the next 11 Countries: the Bootstrapped Autore-gressive Metric Causality Approach[J], Energy Economics , 2014, 44: $14-21$. 